\title{
Soil organic carbon stocks are systematically overestimated by misuse of the parameters bulk density and rock fragment content
}

\author{
Christopher Poeplau, Cora Vos, and Axel Don \\ Thünen Institute of Climate-Smart Agriculture, Bundesallee 50, 38116 Braunschweig, Germany \\ Correspondence to: Christopher Poeplau (christopher.poeplau@thuenen.de) \\ Received: 13 December 2016 - Discussion started: 22 December 2016 \\ Accepted: 21 February 2017 - Published: 13 March 2017
}

\begin{abstract}
Estimation of soil organic carbon (SOC) stocks requires estimates of the carbon content, bulk density, rock fragment content and depth of a respective soil layer. However, different application of these parameters could introduce a considerable bias. Here, we explain why three out of four frequently applied methods overestimate SOC stocks. In soils rich in rock fragments (>30 vol. \%), SOC stocks could be overestimated by more than $100 \%$, as revealed by using German Agricultural Soil Inventory data. Due to relatively low rock fragments content, the mean systematic overestimation for German agricultural soils was $2.1-10.1 \%$ for three different commonly used equations. The equation ensemble as re-formulated here might help to unify SOC stock determination and avoid overestimation in future studies.
\end{abstract}

\section{Introduction}

Size and changes in the soil organic carbon (SOC) pool are major uncertainties in global earth system models used for climate predictions. Accurate estimation of SOC stocks is vital to understanding the links between atmospheric and terrestrial carbon (Friedlingstein et al., 2014). Estimates of global SOC stocks are based on soil inventories from regional to continental scale, involving multiplication of measured carbon content by soil bulk density (BD, oven-dry mass of soil per unit volume) and the depth of the respective soil layer (Batjes, 1996). The content of elements such as carbon and nitrogen in soils is usually determined in an aliquot sample of the fine soil, which is defined as the part of the soil that passes through a $2 \mathrm{~mm}$ sieve (Corti et al., 1998). Coarse mineral fragments $>2 \mathrm{~mm}$, in the following referred to as rock fragments (Poesen and Lavee, 1994), are considered free of SOC (Perruchoud et al., 2000), although this may not be completely true as shown by Corti et al. (2002). Furthermore, living root fragments $>2 \mathrm{~mm}$ are not considered part of SOC, but usually as part of plant biomass. It is thus widely accepted that accurate estimates of SOC stocks should account in some way for the presence of fragments $>2 \mathrm{~mm}$ (Rytter, 2012; Throop et al., 2012).

The accuracy of SOC estimates depends in the first instance on the available data and their quality. Soil organic carbon content of the fine soil is usually measured with high throughput and precision in elemental analysers, while BD and rock fragments content are often only assessed in plotscale studies due to much more elaborate sampling requirements (Don et al., 2007). In regional-scale studies or national soil inventories, BD is therefore often approximated using pedotransfer functions and the fraction of rock fragments is often ignored (Wiesmeier et al., 2012). Stoniness is therefore regarded as the greatest uncertainty in SOC stock estimates (IPCC, 2003). However, even when all parameters are recorded, considerable difference in SOC stocks can arise from varying use of the parameters in equations. Apart from the methodological bias caused by using different methods for determining BD and rock fragment content (BeemMiller et al., 2016; Blake, 1965), the different calculation approaches could lead to systematically different SOC stock estimates if soils contain rock fragments. Several of the approaches commonly used to calculate SOC stocks are not correct and inflate SOC stocks. The aim of this study was 
(i) to reveal the conceptual differences in widely used methods for SOC stock calculation, (ii) to quantify the methodological bias in SOC stocks in a regional-scale soil inventory, (iii) to identify the most affected soil layers and finally (iv) to suggest the most adequate method for unified and unbiased SOC stock calculation.

\section{Materials and methods}

In a preliminary literature review we selected a total of 100 publications for which the method used to calculate SOC stocks was recorded. The search was restricted to publications listed in ISI Web of Knowledge, where "soil carbon stocks" was used as the search term. We ordered the 4915 search results by "relevance", excluded reviews and modelling studies and avoided redundant senior authors (Table $\mathrm{S} 1$ in the Supplement). In the literature we identified four different methods, which vary in use of the parameters BD and rock fragments content (Henkner et al., 2016; LozanoGarcía and Parras-Alcántara, 2013; Poeplau and Don, 2013; Wang and Dalal, 2006):

In method one (M1), a certain volume of soil is sampled, dried and weighed to determine BD. Thereby, no separation into fine soil and coarse soil (rock fragments, roots) fraction is made, while $\mathrm{C}$ concentration is determined in a sieved fine soil sample (usually $<2 \mathrm{~mm}$ ). Soil organic carbon stocks are then calculated as follows:

$$
\text { M1: }
$$

$$
\begin{aligned}
\mathrm{BD}_{\text {sample }} & =\frac{\text { mass }_{\text {sample }}}{\text { volume }_{\text {sample }}} \\
\text { SOCstock }_{i} & =\text { SOCcon }_{\text {fine soil }} \times, \mathrm{BD}_{\text {sample }} \times \operatorname{depth}_{i},
\end{aligned}
$$

where $\mathrm{BD}_{\text {sample }}$ is the bulk density of the total sample, mass $_{\text {sample }}$ is the total mass of the sample, volume sample is the total volume of the sample, SOCstock $i$ is the SOC stock of the investigated soil layer $(i)\left(\mathrm{Mg} \mathrm{ha}^{-1}\right), \mathrm{SOCcon}_{\text {fine soil }}$ is the content of SOC in the fine soil $(\%)$ and depth ${ }_{i}$ is the depth of the respective soil layer $(\mathrm{cm})$. This method does not account for rock fragments at all. In method two (M2), a certain volume of soil is sampled, dried and weighed. However, after sieving, the mass and volume of rock fragments and coarse roots are determined. In the following, we simplify the equations by omitting coarse roots, which is also "common practice", although the volume occupied by roots can be considerably high. This source of error is not further discussed in this study. By approximating a rock fragments density ( $\rho_{\text {rock fragments }}$ ) of $2.6 \mathrm{~g} \mathrm{~cm}^{-3}$ (Don et al., 2007) (root density is usually assumed to be close to $1 \mathrm{~g} \mathrm{~cm}^{-3}$ ), BD of the fine soil is subsequently calculated as
M2:

$$
\begin{aligned}
\mathrm{BD}_{\text {fine soil }} & =\frac{\text { mass }_{\text {sample }}-\text { mass }_{\text {rock fragments }}}{\text { volume }_{\text {sample }}-\frac{\text { mass }_{\text {rock fragments }}}{\rho_{\text {rock fragments }}}}, \\
\text { SOCstock }_{i} & =\text { SOCcon }_{\text {fine soil }} \times \mathrm{BD}_{\text {fine soil }} \times \text { depth }_{i} .
\end{aligned}
$$

Thus in M2, coarse soil content is accounted for in Eq. (3), not in Eq. (4). The opposite is true for the next method (M3), in which the rock fragments fraction (vol. \%/100) is determined, but only applied to reduce the soil volume (Eq. 5), and not to determine $\mathrm{BD}_{\text {fine soil }}$ :

M3: Eq. (1),

$$
\begin{aligned}
\text { SOCstock }_{i} & =\text { SOCcon }_{\text {fine soil }} \times \mathrm{BD}_{\text {sample }} \\
& \times \text { depth }_{i} \times(1-\text { rock fragments fraction })
\end{aligned}
$$

In method four (M4), the coarse soil fraction is accounted for in both equations, i.e. to calculate $\mathrm{BD}_{\text {fine soil }}$ (Eq. 3) and the volume of the fine soil (Eq. 6)

M4: Eq. (3),

$$
\begin{aligned}
\text { SOCstock }_{i} & =\text { SOCcon }_{\text {fine soil }} \times \mathrm{BD}_{\text {fine soil }} \times \text { depth }_{i} \\
& \times(1-\text { rock fragments fraction })
\end{aligned}
$$

It has to be noted that when the term rock fragments fraction in Eq. (5) corresponds to the mass fraction of rock fragments and not to the volume fraction, results of M3 resembles results of M4.

In the German Agricultural Soil Inventory, more than 3000 agricultural soils (cropland and grassland) have been sampled as described by Grüneberg et al. (2014). To date, a total of 2515 sites were sampled and analysed for all relevant parameters (rock fragments content, fine soil mass, carbon content of the fine soil) in five different depth increments: $0-10,10-30,30-50,50-70$ and $70-100 \mathrm{~cm}$. Here, we excluded soils with a SOC content $>8.7 \%$, which are not considered mineral soils anymore (Ad-Hoc-Ag Boden, 2005), giving a total of 2350 sites and 11514 soil samples. The most common soil types sampled were Cambisols (24\%), Anthrosols (16\%), Stagnosols (13\%) and Albeluvisols (11\%) and the parent material was at $93 \%$ of all sites loose sediments of varying origins. We expected the strongest effects in soils with high stoniness and therefore stratified the dataset by rock fragments content (vol. \%). Therefore, we additionally calculated the method-induced potential deviation in SOC stocks as a function of rock fragments content $(0$ 70 vol. \%) for the average $\mathrm{BD}_{\text {fine soil }}$ of the inventory dataset $\left(1.4 \mathrm{~g} \mathrm{~cm}^{-3}\right)$. Due to the fact that method-induced deviations were systematic, we did not conduct statistics. As soon as the rock fragments content is not 0 , there is always a significant difference between calculation methods, no matter how small the differences between methods would be. Data analysis and plotting was performed in the R 3.1.2 environment (R Development Core Team, 2010). 


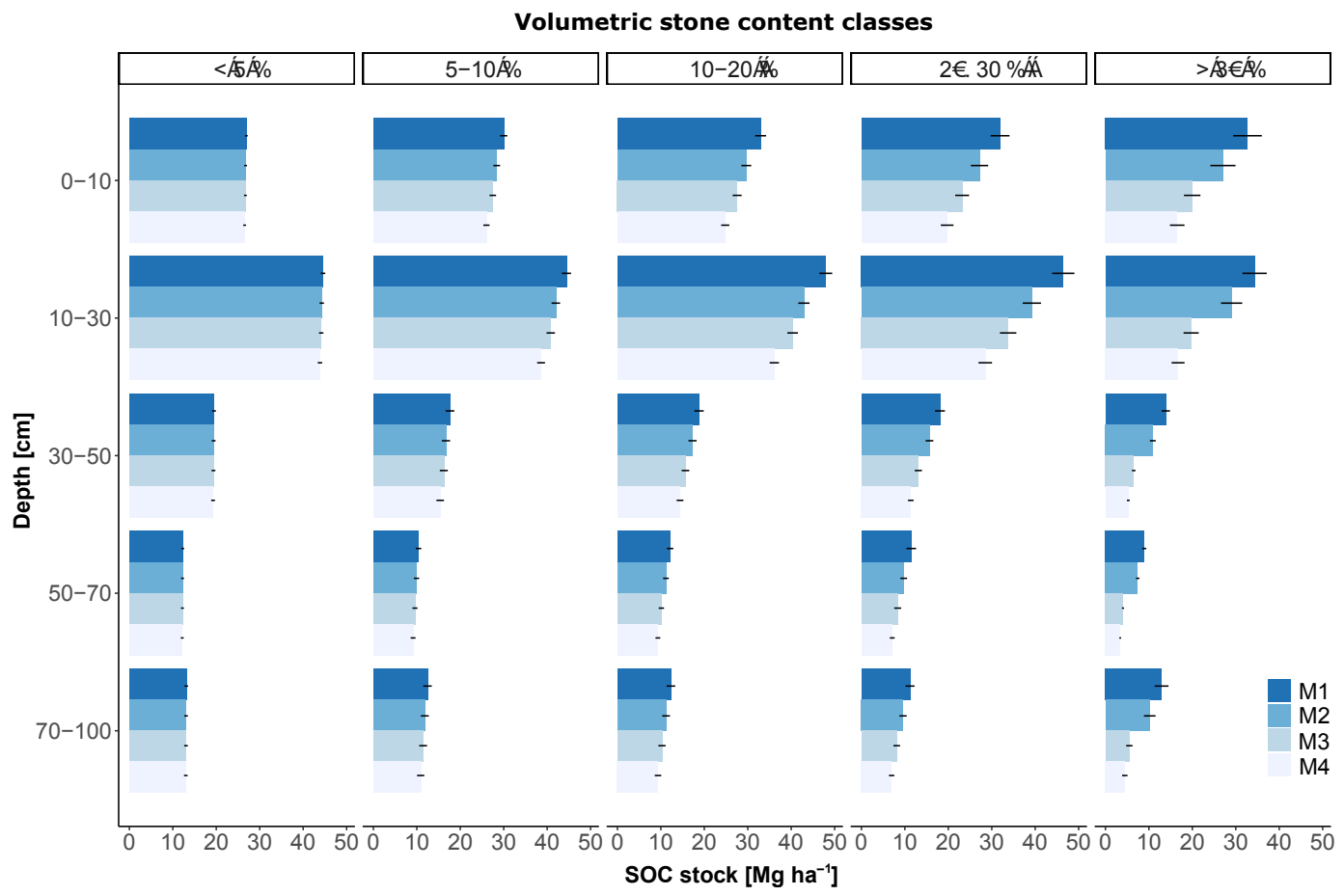

Figure 1. Average soil organic carbon stocks of the German Agricultural Soil Inventory in different depth increments calculated by different calculation methods (M1-M4) for five volumetric rock fragment content classes. Error bars indicate standard errors.

\section{Results and discussion}

\subsection{Bias of three calculation methods to estimate SOC stocks}

Three out of the four SOC calculation methods produced systematically overestimated SOC stocks. These deviations are systematic errors (bias) that cannot be reduced with optimized methods to determine the parameters SOC content, BD and rock fragments content but reduce the accuracy of SOC stock estimates. As expected, the differences in SOC stocks between calculation methods increased with rock fragments content (Fig. 1). This is in line with findings by Rytter (2012), who observed that the method of BD estimation is most important in very stony soils. While differences between methods for soils with a rock fragment content of less than $5 \mathrm{vol} . \%$ were small to almost negligible, M1-M3 deviated strongly from M4 in soils with $>30 \%$ rock fragments (Fig. 1). Since M4 is the closest approximation to reality, the systematic bias was expressed as relative deviation from M4 (Table 1). In soils with $>30 \%$ rock fragments, M1 caused the highest bias of all three calculation methods, overestimating SOC stocks by on average $144 \%$, i.e. more than doubling the real SOC stocks. Methods M2 and M3 also produced biased SOC stocks with 98 and $21 \%$ overestimations for the highest rock fragment content class (>30\% rock fragment content).

Using the average $\mathrm{BD}_{\text {fine soil }}$ of $1.4 \mathrm{~g} \mathrm{~cm}^{-3}$, we plotted the deviation from M4 as a function of volumetric rock fragment content for M1-M3 (Fig. 2). Thereby, M1 and M2 showed exponential responses, while M3 showed a linear response. These responses would increase with decreasing bulk density of the fine soil. The literature review revealed that M1, M2, M3 and M4 were used by 52, 5, 30, and 13 studies respectively. In 19 out of 30 studies using M3, it was unclear whether the correction term $(1-$ rock fragment fraction) referred to the volumetric or gravimetric rock fragment fraction. Thus, in $68-87 \%$ of all studies reviewed, SOC stocks were systematically overestimated assuming a rock fragment fraction $>0$. More than half of the studies reviewed did not account for the rock fragment fraction at all. Cropland was the land-use type in which rock fragment were most often completely ignored. Eighty-five percent of all reviewed cropland studies used M1 to calculate SOC stocks (Table S2). In contrast, $54 \%$ of all studies that used M4 were conducted in forest soils. This might be related to the fact that rock fragment are more abundant in forest soils and that SOC investigations in cropland soils are often restricted to the surface layer with low rock fragment fraction. However, only $17 \%$ of all assessed forest studies used method M4, while M1 was the most often applied (41\%).

The number of soils with high rock fragment contents in the German dataset is limited due to the dominance of parent material from glacio-fluvial deposits (Table 1). Thus, the majority of soils (67-78\%, depending on soil depth increment) had a volumetric rock fragment content of $<5 \%$. As a consequence, the average SOC stocks were only moderately 
Table 1. Fraction of total observations for different volumetric rock fragment content classes in the German Agricultural Soil Inventory and average soil organic carbon stock deviations (\%) from M4 for the calculation methods M1-M3 in different depth increments.

\begin{tabular}{lrrrrr|rrr}
\hline Depth & \multicolumn{3}{c}{ Fraction of total observations } & \multicolumn{3}{c}{ Average relative deviation from M4 } \\
\hline & $<5 \%$ & $5-10 \%$ & $10-20 \%$ & $20-30 \%$ & $>30 \%$ & M1 & M2 & M3 \\
\hline $0-10$ & 78.4 & 12.9 & 5.7 & 1.8 & 1.2 & 6.1 & 3.6 & 2.2 \\
$10-30$ & 72.4 & 14.0 & 6.4 & 3.1 & 4.2 & 7.3 & 4.3 & 2.5 \\
$30-50$ & 68.4 & 10.3 & 6.4 & 4.1 & 10.7 & 8.4 & 5.3 & 2.2 \\
$50-70$ & 67.5 & 9.4 & 6.4 & 4.1 & 12.6 & 8.8 & 5.8 & 2.1 \\
$70-100$ & 68.4 & 9.3 & 5.7 & 3.3 & 13.3 & 10.1 & 6.5 & 2.3 \\
\hline
\end{tabular}

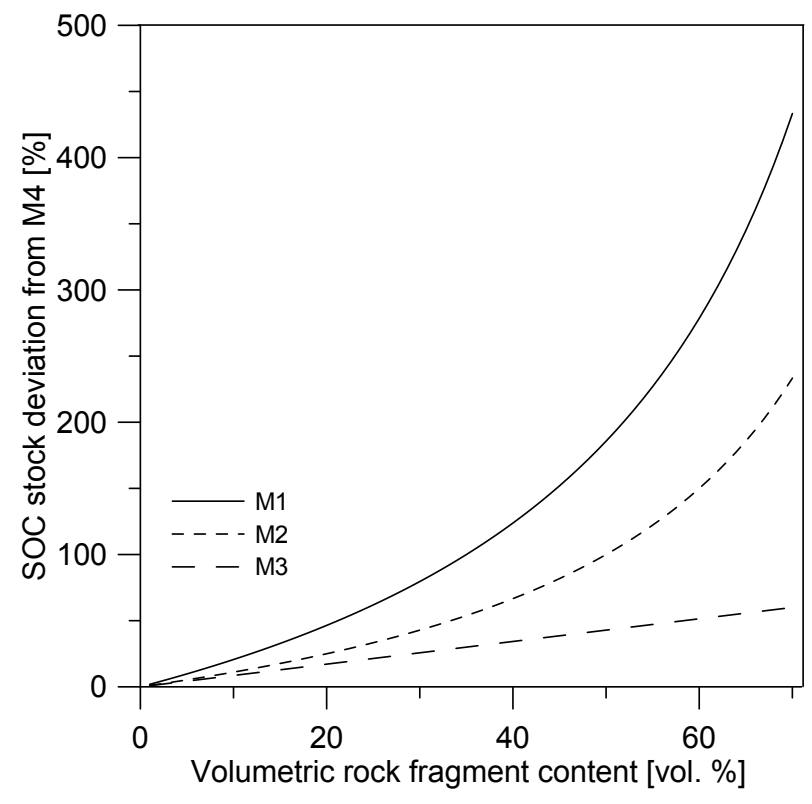

Figure 2. Systematic deviations in SOC stock from calculation method M4 for methods M1-M3 as a function of volumetric rock fragment content. Bulk density of the fine soil was set to $1.4 \mathrm{~g} \mathrm{~cm}^{-3}$ in this example.

influenced by the calculation method (2.1-10.1\% deviation, Table 1). For forests, which are usually found on soils less suitable for agriculture, e.g. due to high stoniness, the bias would be stronger. Overall, the results highlight the importance of a correct use of the parameters BD and rock fragment fraction when calculating SOC stocks.

\subsection{Evaluation of the four different calculation methods}

Since all four methods use the same SOCcon $_{\text {fine soil }}$ due to equal preparation of the fine soil, differences between the calculation methods arise from differences in use of the parameters $\mathrm{BD}$ and rock fragment content. The individual bias of each method is visualized in Fig. 3. In M1, BD of the soil containing SOC (fine soil) is overestimated due to inclusion of rock fragment in the BD estimate. The volume of soil which contains SOC present in the respective soil layer

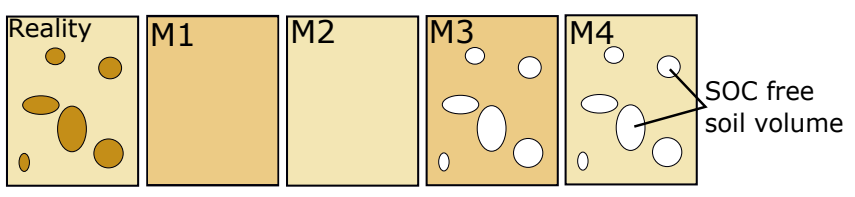

Figure 3. Schematic overview on the four methods applied to estimate the mass of soil needed to calculate soil organic carbon stocks. Different shades of brown are used to indicate different densities: the rock fragment fraction (ellipsoids) has the darkest brown and the fine soil fraction the lightest brown.

is also overestimated, since the rock fragment fraction is not subtracted from the total soil volume (Eq. 2). Thus, M1 "fills" the space occupied by rock fragments with fine soil with an overestimated BD. In the German Agricultural Soil Inventory, only $9 \%$ of all sampled layers were found to be free of rock fragments. Thus, for most soils M1 is not the correct way to calculate SOC stocks. Similarly, M2 overestimates SOCstock $_{i}$ by filling the volume of rock fragments with fine soil. However, BD is calculated and used correctly leading to a smaller systemic overestimation of SOC compared to M1. Finally, M3 correctly accounts for the rock fragment fraction that can be assumed to be SOC-free. However, in M3 an overestimated $\mathrm{BD}$ is applied as in $\mathrm{M} 1$, i.e. $\mathrm{BD}_{\text {sample }}$ and not the $\mathrm{BD}_{\text {fine soil }}$. Methods to estimate $\mathrm{BD}$ and rock fragment content vary, primarily owing to size and abundance of the latter and may have large uncertainty (Blake, 1965; Parfitt et al., 2010; Rytter, 2012). However, the presented difference between calculation methods is independent of the method of determination of the these parameters with one exception: if the sampled soil layer contains no gravel, but only fine soil and rock fragments that exceed the diameter of a soil ring used to determine $\mathrm{BD}_{\text {sample }}$, and this ring is placed at a position (in the profile wall) which is completely free of rock fragments, while the rock fragment content is estimated with a different method and accounted for, then M3 does resemble M4. Bulk density is often determined with soil rings with a volume between 100 and $500 \mathrm{~cm}^{2}$ or soil probes (Walter et al., 2016). In the German Agricultural Soil Inventory, $250 \mathrm{~cm}^{2}$ soil rings are used to determine BD. In $91 \%$ of all soils inventoried, small rock fragments were de- 
tected which end up in the soil ring and have to be corrected for. Thus, method M3 is rarely a correct method to estimate SOC stocks. It is erroneously often cited as the IPCC default method. However, while the equations given in IPCC resemble M3, IPCC provides a footnote that is most likely often overlooked, which states that BD estimates should be corrected for the proportion of "coarse fragments" (IPCC, 2003). Even if the rock fragment fraction might store a certain amount of organic carbon (Corti et al., 2002), which might lead to slight underestimation of SOC stocks in M4, we suggest use of this method in future studies.

\subsection{Proposed equations to calculate SOC stocks}

Bulk density might be of interest as an important soil property. However, for the calculation of SOC stocks alone it is not needed, while it is the fine soil stock of the investigated soil layer $\left(\mathrm{FSS}_{i}, \mathrm{Mg} \mathrm{ha}^{-1}\right)$ that is of interest since it contains the SOC. Thus, the equations in M4 could be reformulated as

$$
\begin{aligned}
\mathrm{FSS}_{i} & =\frac{\text { mass fine soil }_{\text {volume }}}{\text { sample }} \times \text { depth }_{i}, \\
\text { SOCstock }_{i} & =\text { SOCcon }_{\text {fine soil }} \times \mathrm{FSS}_{i} .
\end{aligned}
$$

This has implications for sample preparation: for $\mathrm{BD}_{\text {fine soil }}$ the volume of coarse fragments has to be estimated by weighing rock fragments and coarse roots separately, while $\mathrm{FSS}_{i}$ would only need the total mass of the fine soil contained in the known volume of sample. When using soil probes to sample soil cores with a known volume, FSSi calculation can further be simplified to

$\mathrm{FSS}_{i}=\frac{\text { mass }_{\text {fine soil }}}{\text { surface }_{\text {sample }}}$

where surface sample $_{\text {is }}$ the surface area $\left(\mathrm{cm}^{2}\right)$ of the sampling probe.

\section{Conclusions}

We show here that substantially different methods are used for the calculation of SOC stocks. These methods differ in use of the parameters bulk density and rock fragment content, which causes systematic overestimation of SOC stocks in three out of four, more or less frequently applied methods, or in $68-87$ of 100 publications reviewed. We showed that this overestimation can exceed $100 \%$ in stony soils. For future studies, we suggest to calculate the fine soil stock of a certain soil layer which is to be multiplied with its SOC content to derive unbiased SOC stock estimates. If rock fragments were measured, SOC stocks of existing datasets could also be recalculated, e.g. in the case of resamplings.
Data availability. Data used to calculate SOC stocks in the example are available online at doi:10.17605/OSF.IO/N8W9J (Poeplau, 2017).

\section{The Supplement related to this article is available online at doi:10.5194/soil-3-61-2017-supplement.}

Competing interests. The authors declare that they have no conflict of interest.

Acknowledgements. This study was funded by the German Federal Ministry of Food and Agriculture in the framework of the German Agricultural Soil Inventory.

Edited by: B. van Wesemael

Reviewed by: B. van Wesemael and one anonymous referee

\section{References}

Ad-Hoc-Ag Boden: Bodenkundliche Kartieranleitung, E. Schweizerbart'sche Verlagsbuchhandlung, Hannover, 2005.

Batjes, N.: Total carbon and nitrogen in the soils of the world, Eur. J. Soil Sci., 47, 151-163, 1996.

Beem-Miller, J. P., Kong, A. Y. Y., Ogle, S., and Wolfe, D.: Sampling for Soil Carbon Stock Assessment in Rocky Agricultural Soils, Soil Sci. Soc. Am. J., 80, 1411-1423, 2016.

Blake, G.: Bulk density, Methods of Soil Analysis, Part 1, Physical and Mineralogical Properties, Including Statistics of Measurement and Sampling, 1965, 374-390, 1965.

Corti, G., Ugolini, F. C., and Agnelli, A.: Classing the Soil Skeleton (Greater than Two Millimeters): Proposed Approach and Procedure, Soil Sci. Soc. Am. J., 62, 1620-1629, 1998.

Corti, G., Ugolini, F., Agnelli, A., Certini, G., Cuniglio, R., Berna, F., and Fernández Sanjurjo, M.: The soil skeleton, a forgotten pool of carbon and nitrogen in soil, Eur. J. Soil Sci., 53, 283298, 2002.

Don, A., Schumacher, J., Scherer-Lorenzen, M., Scholten, T., and Schulze, E. D.: Spatial and vertical variation of soil carbon at two grassland sites - Implications for measuring soil carbon stocks, Geoderma, 141, 272-282, 2007.

Friedlingstein, P., Meinshausen, M., Arora, V. K., Jones, C. D., Anav, A., Liddicoat, S. K., and Knutti, R.: Uncertainties in CMIP5 Climate Projections due to Carbon Cycle Feedbacks, J. Clim., 27, 511-526, 2014.

Grüneberg, E., Ziche, D., and Wellbrock, N.: Organic carbon stocks and sequestration rates of forest soils in Germany, Glob. Change Biol., 20, 2644-2662, 2014.

Henkner, J., Scholten, T., and Kühn, P.: Soil organic carbon stocks in permafrost-affected soils in West Greenland, Geoderma, 282, 147-159, 2016.

IPCC: Good practice guidance for land use, land-use change and forestry, Good practice guidance for land use, land-use change and forestry, http://www.ipcc-nggip.iges.or.jp/public/gpglulucf/ gpglulucf.html, 2003. 
Lozano-García, B. and Parras-Alcántara, L.: Land use and management effects on carbon and nitrogen in Mediterranean Cambisols, Agr. Ecosyst. Environ., 179, 208-214, 2013.

Parfitt, R. L., Ross, C., Schipper, L. A., Claydon, J. J., Baisden, W. T., and Arnold, G.: Correcting bulk density measurements made with driving hammer equipment, Geoderma, 157, 46-50, 2010.

Perruchoud, D., Walthert, L., Zimmermann, S., and Lüscher, P.: Contemporary carbon stocks of mineral forest soils in the Swiss Alps, Biogeochemistry, 50, 111-136, 2000.

Poeplau, C.: SOIL data, doi:10.17605/OSF.IO/N8W9J, last access: 9 March 2017.

Poeplau, C. and Don, A.: Sensitivity of soil organic carbon stocks and fractions to different land-use changes across Europe, Geoderma, 192, 189-201, 2013.

Poesen, J. and Lavee, H.: Rock fragments in top soils: significance and processes, Catena, 23, 1-28, 1994.

$\mathrm{R}$ Development Core Team: R: A language and environment for statistical computing, R Foundation for Statistical Computing, Vienna, Austria, 2010.

Rytter, R.-M.: Stone and gravel contents of arable soils influence estimates of C and N stocks, Catena, 95, 153-159, 2012.

Throop, H. L., Archer, S. R., Monger, H. C., and Waltman, S.: When bulk density methods matter: Implications for estimating soil organic carbon pools in rocky soils, J. Arid Environ., 77, 66-71, 2012.
Walter, K., Don, A., Tiemeyer, B., and Freibauer, A.: Determining Soil Bulk Density for Carbon Stock Calculations: A Systematic Method Comparison, Soil Sci. Soc. Am. J., 80, 579-591, 2016.

Wang, W. and Dalal, R.: Carbon inventory for a cereal cropping system under contrasting tillage, nitrogen fertilisation and stubble management practices, Soil Till. Res., 91, 68-74, 2006.

Wiesmeier, M., Sporlein, P., Geuss, U., Hangen, E., Haug, S., Reischl, A., Schilling, B., von Lutzow, M., and Kogel-Knabner, I.: Soil organic carbon stocks in southeast Germany (Bavaria) as affected by land use, soil type and sampling depth, Glob. Change Biol., 18, 2233-2245, 2012. 